\title{
Memantine, Simvastatin, and Epicatechin Inhibit 7-Ketocholesterol-induced Apoptosis in Retinal Pigment Epithelial Cells But Not Neurosensory Retinal Cells In Vitro
}

\author{
Aneesh Neekhra', MD; Julia Tran ${ }^{1}$, BS; Parsa R. Esfahani' ${ }^{1}$, BS; Kevin Schneider ${ }^{1}$, PhD; Khoa Pham ${ }^{1}$, MD \\ Ashish Sharma', MD; Marilyn Chwa ${ }^{1}$, MS; Saurabh Luthra', MD; Ana L. Gramajo', MD; Saffar Mansoor ${ }^{1}$, PhD \\ Baruch D. Kuppermann ${ }^{1}$, MD, PhD; M. Cristina Kenney ${ }^{1,2}$, MD, PhD \\ ${ }^{1}$ Gavin Herbert Eye Institute, University of California, Irvine, California \\ ${ }^{2}$ Department of Pathology and Laboratory Medicine, University of California Irvine, Irvine, CA, USA
}

ORCID:

Aneesh Neekhra: https://orcid.org/0000-0003-1638-9324

M. Cristina Kenney: https://orcid.org/0000-0003-1765-1750

\section{Abstract}

Purpose: 7-ketocholesterol (7kCh), a natural byproduct of oxidation in lipoprotein deposits is implicated in the pathogenesis of diabetic retinopathy and age-related macular degeneration (AMD). This study was performed to investigate whether several clinical drugs can inhibit $7 \mathrm{kCh}$-induced caspase activation and mitigate its apoptotic effects on retinal cells in vitro.

Method: Two populations of retinal cells, human retinal pigment epithelial cells (ARPE-19) and rat neuroretinal cells (R28) were exposed to $7 \mathrm{kCh}$ in the presence of the following inhibitors: Z-VAD-FMK (pan-caspase inhibitor), simvastatin, memantine, epicatechin, and Z-IETD-FMK (caspase-8 inhibitor) or Z-ATAD-FMK (caspase-12 inhibitor). Caspase-3/7, -8, and -12 activity levels were measured by fluorochrome caspase assays to quantify cell death. IncuCyte live-cell microscopic images were obtained to quantify cell counts.

Results: Exposure to $7 \mathrm{kCh}$ for 24 hours significantly increased caspase activities for both ARPE-19 and R28 cells $(P<0.05)$. In ARPE cells, pretreatment with various drugs had significantly lower caspase-3/7, -8 , and -12 activities, reported in $\%$ change in mean signal intensity (msi): Z-VAD-FMK (48\% decrease, $P<0.01$ ), memantine (decreased $47.8 \%$ at $1 \mu \mathrm{M}, P=0.0039$ and $81.9 \%$ at $1 \mathrm{mM}, P<0.001$ ), simvastatin (decreased $85.3 \%$ at 0.01 $\mu \mathrm{M}, P<0.001$ and $84.8 \%$ at $0.05 \mu \mathrm{M}, P<0.001)$ or epicatechin $(83.6 \%$ decrease, $P$ $<0.05)$, Z-IETD-FMK (68.1\% decrease, $P<0.01$ ), and Z-ATAD-FMK (47.7\% decrease, $P=$ $0.0017)$. In contrast, R28 cells exposed to $7 \mathrm{kCh}$ continued to have elevated caspase$3 / 7,-8$, and -12 activities (between $25.7 \%$ decrease and $17.5 \%$ increase in msi, $P>0.05$ ) regardless of the pretreatment.

Conclusion: Several current drugs protect ARPE-19 cells but not R28 cells from 7kChinduced apoptosis, suggesting that a multiple-drug approach is needed to protect both cells types in various retinal diseases.

Keywords: Epicatechin; 7-Ketocholesterol; Memantine 


\section{INTRODUCTION}

Apoptosis is a highly regulated process of programmed cell death critical in various disease states and degenerations. These pathways are implicated in various neurodegenerative diseases (e.g., Alzheimer's disease, Parkinson's disease, amyotrophic lateral sclerosis), ocular diseases (e.g., glaucoma, diabetic retinopathy and age-related macular degeneration [AMD]), and immunologic disorders. ${ }^{[1-6]}$ While treatments for the wet form of AMD rely on inhibiting choroidal neovascularization via anti-vascular endothelial growth factor (anti-VEGF) injections, ${ }^{[7]}$ there is currently no cure for the dry form of AMD.

A pro-apoptotic oxysterol implicated in AMD is 7-ketocholesterol (7kCh), a toxic metabolite generated from the oxidation of cholesterol-esters in low density lipoprotein (LDL), atheromatous plaques, and drusen. ${ }^{6,8-10]} 7 \mathrm{kCh}$ activates three distinct kinase signaling pathways via NFkB, MAPK, and ERK to upregulate proinflammatory cytokines: IL-6, IL-8, and vascular endothelial growth factor (VEGF) which induce neovascularization in the choroid. ${ }^{[7,8,11-13]}$ In previous studies, retinal pigment epithelial (RPE) cells and vascular endothelial cells had an 8- to 10 -fold increase in VEGF levels, ${ }^{[14]}$ and a 2 -fold increase in endothelial smooth muscle cells after exposure to $7 \mathrm{kCh} .{ }^{[15]}$ Our previous studies showed that in both ARPE-19 and rat neuroretinal R28 cell cultures, $7 \mathrm{kCh}$ significantly increased the levels of pro-apoptotic caspase-3, -8, and -12 activities. $^{[16-19]} 7 \mathrm{kCh}$ is also a chemoattractant that directs microglia to the outer retina to produce metalloproteinases that cause breaks in Bruch's membrane and produce pro-angiogenic substances. ${ }^{[11,14,20]}$ A 2019 study showed that $7 \mathrm{kCh}$ intravitreally injected into rat retinas induced apoptosis in photoreceptors and RPE cells

\section{Correspondence to:}

M. Cristina Kenney, MD, PhD. Department of Ophthalmology, Gavin Herbert Eye Institute 843 Health Science Road, Room 2028, Irvine, CA 92697, USA.

E-mail: mkenney@hs.uci.edu

Received: 20-03-2020 Accepted: 21-06-2020

Access this article online

Website: https://knepublishing.com/index.php/JOVR

DOI: $10.18502 /$ jovr.v15i4.7781 and caused microvilli detachment in the outer segment. ${ }^{[10]}$ Thus, the toxic accumulation of $7 \mathrm{kCh}$ over decades may activate cellular processes that predispose patients to age-related ocular pathologies such as AMD. ${ }^{[8]}$

Despite the strong evidence of 7kCh's role in age-related diseases, little is known about its detoxifying mechanisms. A 2019 study showed that compounds such as vitamin E, oleic acid, terpenoids, and polyphenols inhibit 7kCh-induced apoptosis, ${ }^{[1]}$ while resveratrol, an antioxidant and anti-inflammatory stilbenoid found in the skin of grapes and red wine inhibits $7 \mathrm{kCh}$-induced VEGF expression. ${ }^{[22]}$ Successful inhibition by these natural compounds advances our knowledge related to functional food therapies. ${ }^{[21]}$

Thus, it is necessary to explore the potential drugs or inhibitors given the limited body of knowledge on $7 \mathrm{kCh}$ detoxification. The present study investigates six different inhibitors (simvastatin [lipid lowering medication], memantine [used to treat Alzheimer's disease], epicatechin [flavonoid present in green tea], Z-VAD-FMK [pan-caspase inhibitor], Z-IETD-FMK [caspase-8 inhibitor], and Z-ATAD-FMK [caspase-12 inhibitor]) to identify drugs/agents that can block the $7 \mathrm{kCh}$ induced caspase activation. Our results show that these drugs are effective in ARPE-19 cells but not in R28 cells, implicating the need for a multidrug approach or novel therapies to inhibit $7 \mathrm{kCh}$ in various cell types.

\section{METHODS}

\section{Cell Culture}

R28 rat neurosensory cells have properties that resemble those of various human neurosensory cells. The R28 cells derived from retina of post-natal day 6 rats were cultured in Dulbecco's modified Eagle's media,

This is an open access journal, and articles are distributed under the terms of the Creative Commons Attribution-NonCommercial-ShareAlike 4.0 License, which allows others to remix, tweak, and build upon the work non-commercially, as long as appropriate credit is given and the new creations are licensed under the identical terms.

How to cite this article: Neekhra A, Tran J, Esfahani PR; Pham K, Schneider K, Sharma A, Chwa M, Luthra S, Gramajo AL, Mansoor S, Kuppermann BD, Kenney MC. Memantine, Simvastatin, and Epicatechin Inhibit 7-Ketocholesterol-induced Apoptosis in Retinal Pigment Epithelial Cells But Not Neurosensory Retinal Cells In Vitro. J Ophthalmic Vis Res 2020;15:470-480. 
$10 \mu \mathrm{g} / \mathrm{mL}$ gentamicin, $10 \mathrm{mM}$ non-essential amino acids, and high glucose (DMEM high glucose; Invitrogen-Gibco, Carlsbad, CA) with $10 \%$ fetal bovine serum. Despite their clonal origin, R28 cells are characteristically heterogeneous, display both glial and neuronal cell markers, and have functional neuronal properties. ${ }^{[23]}$ R28's diversity of cell types, ability to respond to a variety of stimuli, and differentiation potential makes it an appropriate model for neuroretinal tissue. ${ }^{[24]}$

A 1:1 mixture ( $\mathrm{vol} / \mathrm{vol})$ of Dulbecco's modified Eagle's and Ham's nutrient mixture F-12 was used to grow ARPE-19 cells (ATCC, Manassas, VA); (Invitrogen-Gibco, Carlsbad, CA), $0.37 \%$ sodium bicarbonate, $0.058 \%$ L-glutamine, $10 \%$ fetal bovine serum, antibiotics $(100 \mathrm{U} / \mathrm{ml}$ penicillin $\mathrm{G}, 0.1 \mathrm{mg} / \mathrm{ml}$ streptomycin sulfate, $10 \mu \mathrm{g} / \mathrm{mL}$ gentamicin), $10 \mathrm{mM}$ non-essential amino acids, and an anti-fungal agent (amphotericin-B 2.5 $\mathrm{g} / \mathrm{mL}$ ). ARPE-19 cells are a homogeneous, retinal-derived cell line with functional and structural properties similar to human RPE cells. ${ }^{[25]}$ All cells within the ARPE19 culture express RPE-specific markers such as CRALBP, BEST1, and RPE-65. ${ }^{[26]}$

\section{Cell Plating}

Cells were plated on 24 well plates (Becton Dickinson Labware, Franklin Lakes, NJ) at 150,000 cells per well and incubated at $37^{\circ} \mathrm{C}$ in $5 \% \mathrm{CO}_{2}$ until confluent. Cell incubation was performed in a serum-free media for 24 hours to prevent excessive proliferation. Cells in the experimental group were then pretreated with various inhibitors while the cells in the control group were only exposed to DMSO (the vehicle for $7 \mathrm{kCh}$ ). All experimental cells besides the control cells were then exposed to 30 $\mu \mathrm{g} / \mathrm{ml} 7 \mathrm{kCh}$ for 24 hours before caspase activity was assessed.

\section{Caspase-3/7, -8, and -12 Detection}

Carboxyfluorescein FLICA Caspase Apoptosis Detection kits (Immunochemistry Technologies LLC, Bloomington, MN) were used to quantify cells undergoing caspase-mediated apoptosis. The FLICA Detection Reagent contains a caspase inhibitor sequence linked to a fluorescent carboxyfluorescein probe with an optimal excitation range of 488-492 $\mathrm{nm}$ and an emission range of $515-535 \mathrm{~nm}$. The probe only fluoresces when the FLICA reagent covalently binds to activated caspase-3/7 and -8 in vitro. The fluorescence intensity quantifies the number of whole, living cells undergoing caspase-mediated apoptosis since cells with premature, inactivated, or no caspase activity will not fluoresce. This was measured using the Fluorescence Image Scanning Unit (FMBIO III) instrument (Hitachi, Yokohama, Japan).

Caspase-12 activity was detected using CaspGLOW Fluorescein Caspase-12 staining kit (BioVision). The assay utilizes the caspase12 inhibitor, Z-ATAD-FMK (Ala-Thr-Ala-Aspfluoromethylketone), conjugated to FITC (FITCATAD-FMK) as a marker. FITC-ATAD-FMK irreversibly binds to activated caspase-12 in cells undergoing apoptosis and is cell permeable and nontoxic.

Fresh culture media were used to rinse the wells at 24 hours. Then, $300 \mu \mathrm{l} /$ well of FLICA solution in culture media were placed in the wells for 1 hour. Phosphate buffered saline (PBS) was used to wash the wells three times. The experimental groups were (1) R28 and ARPE-19 cells with $30 \mu \mathrm{g} / \mathrm{ml} 7 \mathrm{kCh}$ alone; (2) R28 and ARPE-19 cells with inhibitor; and (3) R28 and ARPE-19 cells with DMSO. The different inhibitors used were $1 \mu \mathrm{M}$ and $1 \mathrm{mM}$ memantine (Alexis Biochemical, San Diego), $0.01 \mu \mathrm{M}$ and $0.05 \mu \mathrm{M}$ simvastatin (Merck and Co., Whitehouse Station, NJ), $5 \mu \mathrm{M}$ epicatechin (Sigma Aldrich Inc, St Louis, MO), the pan-caspase inhibitor Z-VAD-FMK (Val-Ala-Asp-fluoromethylketone, Immunochemistry Technologies LLC, Bloomington, $\mathrm{MN}$ ), the caspase-8 inhibitor (Z-IETD-FMK, Iso-GluThr-Asp-fluoromethylketone, Calbiochem, La Jolla, CA), and caspase-12 inhibitor (Z-ATAD-FMK, AlaThr-Ala-Asp-fluoromethylketone, Calbiochem, La Jolla, CA). The inhibitors were added to the culture medium 1 hour before exposing cells to $7 \mathrm{kCh}$.

In addition to the experimental groups, we also analyzed the following control groups: (1) untreated R28 cells and ARPE-19 cells without FLICA or CaspGLOW to exclude autofluorescence from cells; (2) untreated R28 and ARPE-19 cells with FLICA or CaspGLOW for comparison of caspase activity of treated cells; (3) tissue culture plate wells (without cells) with buffer alone to represent the background levels; (4) tissue culture plate wells without cells with culture media and DMSO in order to exclude cross-reaction of culture media and/or DMSO with the plastic material of the tissue culture 
plate or cross-reaction of FLICA or CaspGLOW; (5) R28 cells and ARPE-19 cells with DMSO and FLICA to account for any cross-fluorescence due to the cross-reaction of untreated cells with DMSO; and (6) untreated R28 and ARPE-19 cells with negative control Z-FA-FMK and FLICA as a control for the pan caspase inhibitor.

IncuCyte ${ }^{\circledR}$ Live-Cell Imaging Analysis was used to capture fluorescent images in real time. NucLight Rapid Red and Caspase-3/7 Green reagents were used to stain cells in 96-well plates at 5,00010,000 cells/well. The NucLight Rapid Red reagent quantifies the amount of cell proliferation in IncuCyte live-cell images by staining the nuclei of living cells. The Caspase-3/7 Green reagent contains an oligopeptide cleavage sequence (DEVD) conjugated to a DNA-binding dye. The green reagent labels apoptotic cells at an emission maximum of $533 \mathrm{~nm}$ once the sequence is cleaved by caspase-3/7. Images were captured per well every 3 hours for five days with Brightfield, Red, and Green channels. Apoptosis due to caspase-3/7 activity is discriminated from live and necrotic cells by overlapping the signal counts from NucLight Red with the Caspase-3/7 green.

\section{Statistical Analysis}

ANOVA using GraphPad Prism 3.0 version statistics program (GraphPad Software Inc., San Diego, CA) was used for statistical analysis of the data. The data within each experiment were compared using the Newman-Keuls multiple comparison test. Mean \pm standard error of mean (SEM) was used to present the data. Experiments were performed in triplicate. $P$-values $<0.05$ were considered statistically significant.

\section{RESULTS}

Pan-caspase Inhibitor Z-VAD-FMK Reduces Caspase-3/7 Activity in Only ARPE-19 Cells

ARPE-19 cells exposed to $7 \mathrm{kCh}$ had increased caspase-3/7 activity $(31,311 \pm 766.7 \mathrm{msi}, P<$ 0.0001) compared to the ARPE-19 cells exposed only to DMSO $(6,086 \pm 910 \mathrm{msi}$, Figure $1 \mathrm{~A})$. Caspase-3/7 activity in ARPE-19 cells decreased significantly at $48.0 \%$ following pretreatment with Z-VAD-FMK $(16,278 \pm 323.1 \mathrm{msi}, P<0.0001$, Figure 1A). R28 cells exposed to $7 \mathrm{kCh}$ had increased caspase-3/7 activity (34,014 \pm 2,126 $\mathrm{msi}, \quad P=0.0001$ ) compared to the R28 cells exposed only to DMSO $(1,975 \pm 234.5 \mathrm{msi}$, Figure 1B). Caspase-3/7 activity in R28 cells did not decrease significantly at $12.3 \%$ following pretreatment with Z-VAD-FMK $(29,805 \pm 3,007$ $\mathrm{msi}, P>0.05$, Figure 1B). The pan-caspase inhibitor Z-VAD-FMK was not able to protect the R28 cells.

$1 \mu \mathrm{M}$ and $1 \mathrm{mM}$ Memantine Reduce Caspase3/7 Activity in Only ARPE-19 Cells

ARPE-19 cells exposed to $7 \mathrm{kCh}$ had increased caspase-3/7 activity $(32,972 \pm 1,891 \mathrm{msi}, P=$ 0.001) compared to ARPE-19 cells exposed only to DMSO $(12,791 \pm 1,501 \mathrm{msi}$, Figure $2 \mathrm{~A})$. Caspase-3/7 activity in ARPE-19 cells decreased significantly at $47.8 \%$ following pretreatment with $1 \mu \mathrm{M}$ memantine $(17,218 \pm 1,835 \mathrm{msi}, P=0.003$, Figure $2 \mathrm{~A})$ and even more so at $81.9 \%$ with $1 \mathrm{mM}$ memantine $(5,969 \pm 1,596 \mathrm{msi}, P<0.001$, Figure 2A). R28 cells exposed to $7 \mathrm{kCh}$ had increased caspase-3/7 activity $(31,974 \pm 2,599 \mathrm{msi}, P<0.001)$ compared to R28 cells exposed only to DMSO (2,355 \pm $254.4 \mathrm{msi}$, Figure 2B). Caspase-3/7 activity in R28 cells did not decrease significantly following pretreatment with $1 \mu \mathrm{M}$ memantine $(33,850 \pm$ $1,894 \mathrm{msi}, P>0.05$, Figure $2 \mathrm{~B}$ ) nor with 1 $\mathrm{mM}$ memantine $(33,422 \pm 863.7 \mathrm{msi}, P>0.05$, Figure 2B). Neither concentration of the NMDA inhibitor memantine protected the R28 cells from apoptosis.

\section{$0.01 \mu \mathrm{M}$ and $0.05 \mu \mathrm{M}$ Simvastatin Reduce Caspase-3/7 Activity in Only ARPE-19 Cells}

ARPE-19 cells exposed to 7kCh had increased caspase-3/7 activity $(32,972 \pm 1,891 \mathrm{msi}, P=0.001)$ compared to ARPE-19 cells exposed only to DMSO $(12,791 \pm 1,501$ msi, Figure $2 \mathrm{C})$. Caspase-3/7 activity in ARPE-19 cells decreased significantly at $85.3 \%$ following pretreatment with $0.01 \mu \mathrm{M}$ simvastatin $(4,849 \pm 500.2 \mathrm{msi}, P<0.001$, Figure $2 \mathrm{C})$ and at $84.8 \%$ with $0.05 \mu \mathrm{M}$ simvastatin $(5,016 \pm 968.5 \mathrm{msi}$, $P<0.001$, Figure 2C). R28 cells exposed to $7 \mathrm{kCh}$ had increased caspase-3/7 activity (31,974 $\pm 2,599$ msi, $P<0.001)$ compared to R28 cells exposed only to DMSO $(2,355 \pm 254.4 \mathrm{msi}$, Figure 2D). Caspase-3/7 activity in R28 cells did not decrease significantly at $8.3 \%$ following pretreatment with 
ARPE-19 Caspase-3/7 Activity after Treatment with Z-VAD-FMK

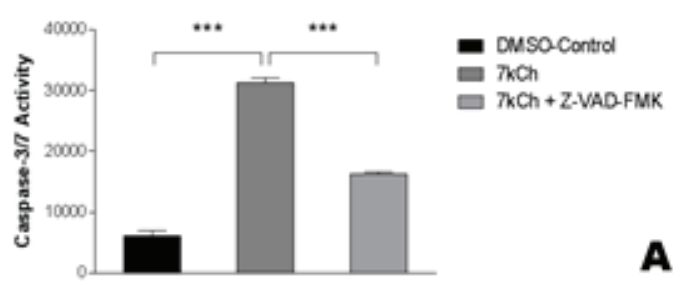

R28 Caspase-3/7 Activity after Treatment with Z-VAD-FMK

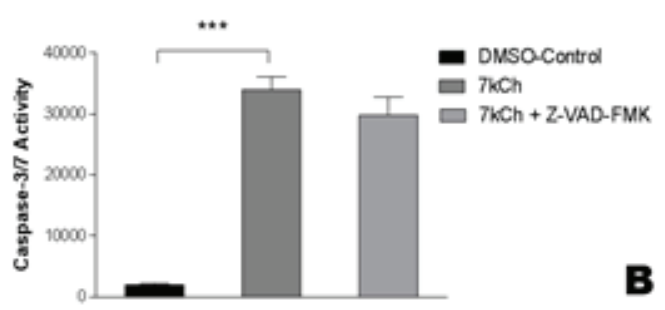

Figure 1. Caspase-3/7 activity in 7kCh-treated ARPE-19 and R28 cells in response to 7kCh alone or pretreatment with Z-VAD-FMK. Cells exposed to $7 \mathrm{kCh}$ alone increased caspase-3/7 activity*** (A-B). ARPE-19 cells pretreated with Z-VAD-FMK decreased caspase-3/7 activity*** (A). In contrast, R28 cells pretreated with Z-VAD-FMK did not have decreased caspase-3/7 activity (B).

${ }^{*} P<0.05,{ }^{* *} P<0.01,{ }^{* * *} P<0.001$. The error bars represent the standard error of the mean (SEM) of measurements for the three conditions in three separate runs $(n=9, A-B)$.

$0.01 \mu \mathrm{M}$ simvastatin $(29,316 \pm 897.9 \mathrm{msi}, P>$ 0.05 , Figure 2D) nor with $0.05 \mu \mathrm{M}$ simvastatin, which had a slight increase in activity at $17.5 \%$ $(37,575 \pm 1,629 \mathrm{msi}, P>0.05$, Figure 2D). Neither concentration of simvastatin protected the R28 cells from apoptosis.

\section{$5 \mu \mathrm{M}$ Epicatechin Reduces Caspase-3/7 Activity in Only ARPE-19 Cells}

ARPE-19 cells exposed to 7kCh had increased caspase-3/7 activity $(32,181 \pm 4,839 \mathrm{msi}, P=0.005$, Figure 2E) compared to ARPE-19 cells exposed only to DMSO $(5,936 \pm 491.4 \mathrm{msi}$, Figure 2E). Caspase-3/7 activity in ARPE-19 cells decreased significantly at $83.6 \%$ following pretreatment with $5 \mu \mathrm{M}$ epicatechin $(5,263 \pm 4,344 \mathrm{msi}, P<$ 0.05 , Figure 2E). R28 cells exposed to $7 \mathrm{kCh}$ had increased caspase-3/7 activity $(34,720 \pm$ $3,197 \mathrm{msi}, P<0.001$, Figure $2 \mathrm{~F}$ ) compared to R28 cells exposed only to DMSO $(2,488 \pm 116.3$ msi, Figure 2F). Caspase-3/7 activity in R28 cells decreased at $25.7 \%$ following pretreatment with $5 \mu \mathrm{M}$ epicatechin $(25,806 \pm 977.5 \mathrm{msi}, P=0.05$, Figure $2 \mathrm{~F}$ ), but the $p$-value was not significant.

Representative IncuCyte live-cell images of ARPE-19 cells treated with DMSO-Control, 7kCh, and $7 \mathrm{kCh}$ with epicatechin, respectively, are shown in Figure 2G. 7kCh increased NucLight Red signal, Caspase-3/7 green signal, and overlap signal counts at 24 hours (Figure 2G, second row) compared with DMSO-Control (Figure 2G, first row) in ARPE-19 cells. These counts are reduced when cultures are pretreated with inhibitors such as epicatechin before exposure to $7 \mathrm{kCh}$ (Figure 2G, third row).

\section{Caspase-8 Inhibitor Z-IETD-FMK Reduces Caspase-8 Activity in Only ARPE-19 Cells}

ARPE-19 cells exposed to $7 \mathrm{kCh}$ had increased caspase-8 activity $(28,037 \pm 398 \mathrm{msi}, P<0.001$, Figure 3A) compared to ARPE-19 cells exposed only to DMSO $(7,210 \pm 478.8 \mathrm{msi}$, Figure $3 \mathrm{~A})$. Caspase-8 activity in $7 \mathrm{kCh}$ exposed ARPE-19 cells was significantly reduced at $68.1 \%$ following pretreatment with Z-IETD-FMK $(8,952 \pm 283 \mathrm{msi}, P$ $<0.01$, Figure 3A). R28 cells exposed to $7 \mathrm{kCh}$ had increased caspase- 8 activity $(34,734 \pm 944.5 \mathrm{msi}, P$ $=0.001$, Figure $3 \mathrm{~B}$ ) compared to R28 cells exposed only to DMSO (11,043 $\pm 55.5 \mathrm{msi}$, Figure 3B). Caspase-8 activity in 7kCh-exposed R28 cells was not significantly reduced at $8.4 \%$ by pretreatment with Z-IETD-FMK $(31,825 \pm 3,073, P>0.05$, Figure 3B).

\section{Caspase-12 Inhibitor Z-ATAD-FMK Reduces Caspase-12 Activity in Only ARPE-19 Cells}

ARPE-19 cells exposed to $7 \mathrm{kCh}$ had increased caspase-12 activity $(38,585 \pm 1,804 \mathrm{msi}, P<0.001$, Figure 3C) compared to ARPE-19 cells exposed only to DMSO $(15,351 \pm 636.5 \mathrm{msi}$, Figure $3 \mathrm{C})$. Caspase-12 activity in 7kCh-exposed ARPE-19 cells was significantly reduced at $47.7 \%$ by pretreatment with Z-ATAD-FMK $(20,175 \pm 719 \mathrm{msi}, P=0.001$, Figure $3 C)$. R28 cells exposed to $7 \mathrm{kCh}$ had an increased caspase- 12 activity $(31,234 \pm 4,445 \mathrm{msi}$, $P<0.05$, Figure 3D) compared to R28 cells exposed only to DMSO $(10,043 \pm 944.5 \mathrm{msi}$, Figure 3D). Caspase-12 activity in 7kCh-exposed R28 cells was not significantly reduced at $9.1 \%$ by 


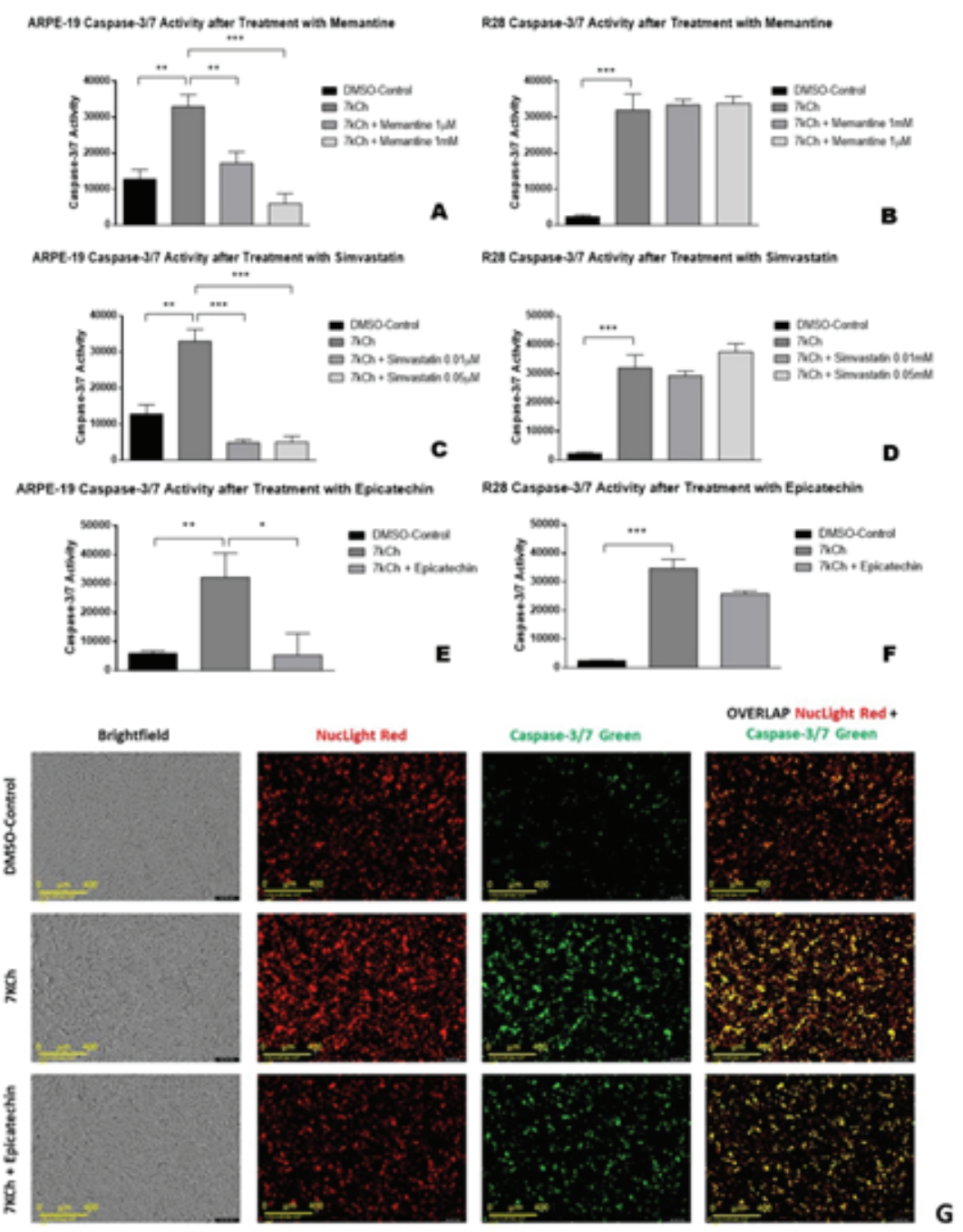

Figure 2. Caspase-3/7 activity in 7kCh-treated ARPE-19 and R28 cells after pretreatment with memantine, simvastatin, or epicatechin.

All cells exposed to 7kCh alone increased caspase-3/7 activity (A-F). Pretreatment of ARPE-19 cells with $1 \mu \mathrm{M}^{* *}$ and $1 \mathrm{mM}^{* * *}$ memantine (A) $0.01 \mu \mathrm{M}^{* * *}$ and $0.05 \mu \mathrm{M}^{* * *}$ simvastatin (C), or $5 \mu \mathrm{M}$ epicatechin* $(\mathrm{E})$ showed decreased caspase-3/7 activity. In contrast, R28 cells pretreated with $1 \mu \mathrm{M}$ and $1 \mathrm{mM}$ memantine (B) $0.01 \mu \mathrm{M}$ and $0.05 \mu \mathrm{M}$ simvastatin (D), or $5 \mu \mathrm{M}$ epicatechin (F) did not have significantly decreased caspase-3/7 activity. Representative IncuCyte live-cell images of DMSO-Control, 7kCh, and 7kCh with epicatechin-treated ARPE-19 cells at 24 hours (G). There are no major differences among treatments detected with brightfield microscopy (G, first column). ARPE-19 cells stressed with 7kCh demonstrate increased nuclear staining number, increased caspase-3/7 signal number, and an increased overlap signal number (G, second row). These counts decrease when ARPE-19 cells are pretreated with epicatechin before $7 \mathrm{kCh}$ (G, third row).

${ }^{*} P<0.05,{ }^{* *} P<0.01,{ }^{* * *} P<0.001$. The error bars represent the standard error of the mean (SEM) of measurements for the four conditions in three separate runs $(n=12, A-D)$ and three conditions in three separate runs $(n=9, E-F)$. Scale bar $=400 \mu M(G)$.

pretreatment with Z-ATAD-FMK $(28,379 \pm 4518 \mathrm{msi}$, $P>0.05$, Figure 3D).

\section{DISCUSSION}

This study emphasized 7kCh's role in caspase activation and highlighted several clinical drugs that protected RPE cells but not
R28 cells from 7kCh-induced apoptosis. Research in the past two decades has strongly supported 7kCh's role in AMD pathogenesis. $7 \mathrm{kCh}$ from $\mathrm{LDL}$ is esterified via two enzymes, cPLA2 $\alpha$ and SOAT1, to $7 \mathrm{kCh}-$ fatty acid esters (7KFAEs), and effluxed by $\mathrm{HDL}$ to the liver for bile acid production. ${ }^{[27]}$ Cholesterol levels may therefore contribute to ocular disease as high serum levels of 
ARPE-19 Caspase-8 Activity after Treatment with Z-IETD-FMK

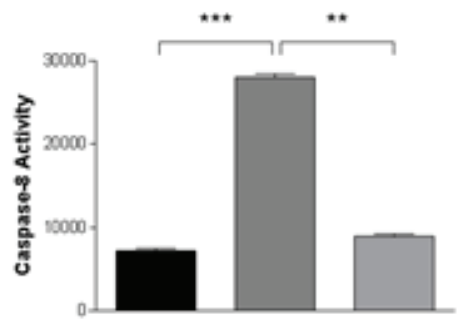

ARPE-19 Caspase-12 Activity after Treatment with Z-ATAD-FMK

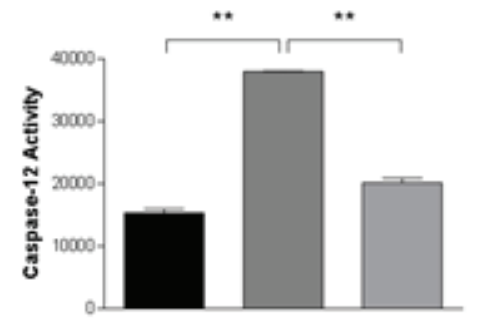

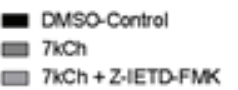

A

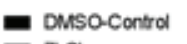
$\square 7 \mathrm{kCh}$ 7KCh +Z-ATAD-FMK
R28 Caspase-8 Activity after Treatment with ZJETD-FMK

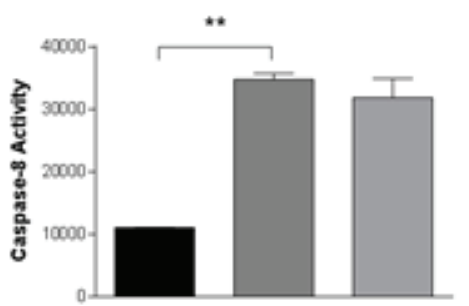

- DMSa-Cortrol

마 $7 \mathrm{kh}$

$\square 7 \mathrm{kCh}+$ Z-IETD-FMK

B

R28 Caspase-12 Activity after Treatment with Z-ATAD-FMK

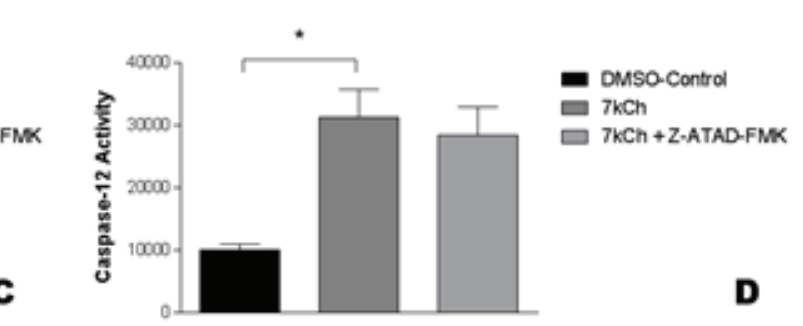

Figure 3. Caspase-8 and -12 activity in 7kCh-treated ARPE-19 and R28 cells in response to 7kCh alone or pretreatment with ZIETD-FMK or Z-ATAD-FMK.

All cells exposed to $7 \mathrm{kCh}$ alone showed increased caspase-3/7 activity (A-F). ARPE-19 cells pretreated with Z-IETD-FMK** (A) or Z-ATAD-FMK** (C) showed decreased caspase-8 and -12 activity, respectively. In contrast, R28 cells pretreated with Z-IETD-FMK (B) or Z-ATAD-FMK (D) did not show decreased caspase-8 nor -12 activities, respectively.

${ }^{*} p<0.05,{ }^{* *} p<0.01,{ }^{* * *} p<0.001$. The error bars represent the standard error of the mean (SEM) of measurements for the three conditions in three separate runs $(n=9, A-D)$.

LDL or 7KFAEs (which revert to 7kCh), or low levels of $\mathrm{HDL}$ can result in increased $7 \mathrm{kCh}$ levels. ${ }^{[27]} 7 \mathrm{kCh}$ may also accumulate over time from natural mechanisms such as the rhodopsin cycle and other photo-oxidative processes. $^{[28]}$ Compared to controls, $7 \mathrm{kCh}$ was found at 6- to 50-fold higher levels in RPE and photoreceptor inner segments of photodamaged rat retinas, ${ }^{[9]}$ and at 4 -fold levels in Bruch's membrane and neuroretinal cells in photodamaged monkey retinas. ${ }^{[14,28]}$ Excess $7 \mathrm{kCh}$ can trigger caspase pathways, excess reactive oxygen species (ROS) production, endothelial dysfunction, breaks in Bruch's membrane, induction of cytokines IL- 6 and IL-8, and neovascularization in the choroid [16-20, 29-31], which are all consistent with AMD. Additional damage includes increased levels of DNA fragmentation and increased chromatin condensation in both ARPE-19 and R28 cells. ${ }^{[32]}$ $7 \mathrm{kCh}$ also damages mitochondria by inducing reactive oxygen/nitrogen species, reducing the mitochondrial membrane potential by 2.2 -fold $(P$ $<0.001$ ), and decreasing levels of intact $16.2-\mathrm{kb}$ mtDNA. ${ }^{[16]}$
The clinically available inhibitors used in this study all prevented $7 \mathrm{kCh}$ induced caspase-3/7 activation in ARPE-19 cells but not R28 cells:

(1) Memantine is a moderate-affinity, noncompetitive antagonist of the glutamatergic N-methyl-D-aspartate (NMDA) receptors. It suppresses glutamate-excitotoxicity in animal models associated with neurological diseases such as Alzheimer's, vascular dementia, and retinal ganglion cell death after ischemic strokes. ${ }^{[33-37]}$ By inhibiting downstream p53 and calpain-caspase-3, it reduces $\mathrm{Ca}^{2+}$-dependent production of $\mathrm{NO}$ and $\mathrm{O} 2(-)$ and halts neuronal apoptosis in rats with middle cerebral artery occlusion. ${ }^{[36,38,39]}$ A previous study showed that memantine reduces caspase-3/7 activity in staurosporine-treated neuronal cells. ${ }^{[40]}$ The present study showed $1 \mu \mathrm{M}$ and $1 \mathrm{mM}$ of memantine reduced caspase- $3 / 7$ activity by 47.8\% and $81.9 \%$ in ARPE-19 cells, respectively, but only $5.9 \%$ and $4.5 \%$ in R28 cells (Figures 2A-2B) despite evidence of immunoreactivity to NMDA and GABAa receptors. ${ }^{[41]}$ This may be because memantine can upregulate brainderived neurotrophic factor through the PI3-K/Akt 
pathway independent of NMDA receptors. ${ }^{[42]}$ Furthermore, R28 cells derived from six-day old rat retina are not fully differentiated and may not have well-developed NMDA receptors. R28 cultures are also heterogeneous and memantine may preferentially affect neural cells with NMDA receptors over non-neural glial cells. ${ }^{[23]}$

(2) Simvastatin is a hydrophobic drug that inhibits 3-Hydroxy-3-methyl-glytaryl coenzyme A (HMG-CoA) reductase and is frequently utilized to reduce serum LDL in hyperlipidemic patients. $^{[43]}$ Besides its lipid-lowering effects, it is also neuroprotective and upregulates $\mathrm{Bcl}-2$, a major cell survival protein, ${ }^{[44,45]}$ and induces Hsp27, a heat shock protein that promotes retinal ganglion cell survival. ${ }^{[46]}$ In rats with streptozotocininduced diabetes, therapeutic levels of simvastatin slowed progression of diabetic retinopathy by reducing VEGF activation, vascular permeability, and endothelial-leukocyte adherence. ${ }^{[47]}$ The effects of statins are notably biphasic: low concentrations of statins are pro-angiogenic, while high concentrations are angiostatic. ${ }^{[48-50]}$ Higher concentrations can also induce caspase3/7 apoptosis in human monocytes, pericytes, and tumor cells. ${ }^{[50-52]}$ Our results show that $0.01 \mu \mathrm{M}$ and $0.05 \mu \mathrm{M}$ of simvastatin reduced caspase-3/7 activity by $85.3 \%$ and $84.8 \%$, respectively, in ARPE19 cells (Figure 2C), while $0.05 \mu \mathrm{M}$ simvastatin increased caspase activity by $17.5 \%$ in R28 cells (Figure 2D). The therapeutic dose in ARPE-19 cells was toxic in R28 cells, suggesting underdeveloped drug import/export systems or excess HMG-CoA reductase concentrations in R28 cells, but further studies are needed.

(3) Epicatechin is a powerful antioxidant flavanol found in many plant-based foods such as grapes, dark chocolate, and green tea. It is commonly used to reduce oxidative damage by inhibiting nicotinamide adenine dinucleotide phosphate (NADPH) oxidase and maintaining nitric oxide (NO) synthase, which prevents oxidized LDL endothelial dysfunction implicated in dementia. ${ }^{[53-55]}$ It can also decrease levels ROS in the hippocampus of rat models with hypertension and Alzheimer's. ${ }^{[56]}$ Other studies show that epigallocatechin gallate, a derivative with phenolic hydroxyl, injected into rat retinas attenuated sodium nitroprusside-induced oxidative stress in retinal ganglion cells. ${ }^{[57]}$ Our results show that epicatechin significantly reduced caspase- $3 / 7$ activity by $83.6 \%$ in ARPE- 19 cells, but only $25.7 \%$ in R28 cells $(P=0.05$. Figures $2 \mathrm{E}-$ $2 \mathrm{~F})$. Unlike the first two inhibitors, epicatechin's borderline $p$-value suggests it protects R28 cells by decreasing general oxidative burden. Thus, targeting upstream ROS production via NADPH oxidase may protect multiple retinal cell types more effectively than targeting specific downstream enzymes or receptors. These results are consistent with those obtained by IncuCyte ${ }^{\circledR}$ Live-Cell Imaging Analysis which captures caspase-3/7-mediated apoptosis in real-time images (Figure 2G). The overlapped signal (Figure 2G, fourth column) shows increased caspase activity with $7 \mathrm{kCh}$ (Figure 2G, second row) that was reduced with epicatechin pretreatment (Figure 2G, third row). Figure $2 G$ shows the representative images of ARPE-19 cells treated with DMSO-control (first row), 7kCh (second row), and pretreated with epicatechin (third row). Similar image results were obtained with ARPE-19 cells pretreated with simvastatin or memantine.

(4) Z-VAD-FMK is a direct pan-caspase inhibitor that irreversibly binds the catalytic site of various caspase proteases. It prevented cell shrinkage and DNA fragmentation due to caspase-2, $-3,-6$, and -8 in flounder immune cells, ${ }^{[58]}$ and prevented increases in p53, PARP-1, and caspase-3 levels after 35 hours of glucose deprivation in retinal ganglion cells. ${ }^{[59]}$ In ARPE-19 cells, the Z-VADFMK reduced 7-kCh-induced caspase-3/7 activity by $48.0 \%$ but did not protect R28 (12.3\%).

(5) Z-IETD-FMK is a direct caspase-8 inhibitor that disrupts the extrinsic caspase pathway. It reduced caspase- 8 activity by $68.1 \%$ in ARPE-19 cells but had no protective effects in neuroretinal cells (8.4\%).

(6) Z-ATAD-FMK is a caspase-12 inhibitor that disrupts the endoplasmic reticulum stress-induced caspase pathway. In ARPE-19 cells, it reduced caspase-12 activity by $47.7 \%$. In contrast, there was no significant effect on R28 cells, with only $9.1 \%$ decrease in caspase activity.

Previous studies demonstrated that a component of cigarette smoke, benzo(e)pyrene $[\mathrm{B}(\mathrm{e}) \mathrm{P}]$, also induces caspase-3/7 activity in ARPE19 cells and was inhibited by genistein, resveratrol, and memantine but not calpain, BTIC, simvastatin, or epicatechin. ${ }^{[60]}$ When combined with the current study's results, memantine could reverse both $\mathrm{B}(\mathrm{e}) \mathrm{P}$ - and $7 \mathrm{kCh}$-induced caspase- $3 / 7$ activities in ARPE-19 cells, but simvastatin and epicatechin only 
reversed activity induced by $7 \mathrm{kCh}$ not $\mathrm{B}(\mathrm{e}) \mathrm{P}$. This indicates that the same cell type can have distinct pathways to activate and inhibit caspase- $3 / 7$, depending on the insult.

Likewise, the current study suggests that different cell types have distinct pathways to activate and inhibit apoptosis induced by $7 \mathrm{kCh}$. None of the drugs significantly reduced caspase activity in R28 cells, which strongly implies that tissue characteristics or processes maintain apoptosis in the presence of inhibitors. As mentioned previously, R28 cells are retinal precursor cells from six-day old rats that express genes and proteins specific to their developmental age, which may not include receptors that respond to the drugs. ${ }^{[41]}$ Furthermore, this heterogeneous population has cell types with distinct morphologies, biochemical characteristics, and neuronal-specific cell markers. A subset of R28 cells have receptors to neurotransmitters such as dopamine, serotonin, glycine, and acetylcholine; other cells have receptors that respond to NMDA and GABA agonists; still others show immunoreactivity to GluR1, GluR2, and GluR3. ${ }^{[24,41]}$ In contrast, ARPE-19 cells are a homogeneous population of RPE cells that grow in a monolayer, express the same receptors and RPE-selective markers like CRALBP, and have the same cobblestone morphology. ${ }^{[61]}$ Thus, receptoror enzyme-specific drugs such as the caspase inhibitors, memantine, or simvastatin will affect all ARPE-19 cells equally and the global response is additive $(-47.7 \%$ to $-85.3 \%$ change in caspase activity, all $p$-values < 0.05). In contrast, only a fraction of R28 cells that express the target enzyme or receptor will be affected, and the global response is represented only by the subset $(+17.5 \%$ to $-25.7 \%$ change in caspase activity, all $p$-values $>0.05)$.

In summary, the current study quantified caspase-3/7 activity as a marker of apoptosis between human ARPE-19 cells and rat R28 cells after treatment with $7 \mathrm{kCh}$ and various inhibitors. $7 \mathrm{kCh}$ significantly induced caspase-3/7 for both cultures, yet pretreatment with anti-apoptotic drugs (memantine, simvastatin, epicatechin, Z-VAD-FMK, etc.) consistently reduced caspase activities only in the ARPE-19 cells. This discrepancy in caspase deactivation between ARPE-19 and R28 cells may be related to the differences in the heterogeneity of the cell population or the age and species of the original tissue. Ultimately, the etiology of AMD is multifactorial and future treatments may utilize combination therapy to inhibit common toxins, like $7 \mathrm{kCh}$ and $\mathrm{B}(\mathrm{e}) \mathrm{P}$, that affect multiple retinal cell targets.

\section{Acknowledgments}

The authors are grateful to Dr. Gail M. Seigel from the Center for Hearing and Deafness, University at Buffalo, The State University of New York, Buffalo, New York and SUNY Eye Institute for all her contributions and particularly for providing the R28 cell cultures.

\section{Financial Support and Sponsorship}

This work was supported by the Discovery Eye Foundation, Polly and Michael Smith, Edith and Roy Carver, and NEI R01 EY0127363 (MCK and in part by an Unrestricted Departmental Grant from Research to Prevent Blindness. The authors are also thankful to the Institute for Clinical and Translational Science (ICTS) at University of California Irvine.

\section{Conflicts of Interest}

There are no conflicts of interest.

\section{REFERENCES}

1. Favaloro B, et al. Role of apoptosis in disease. Aging 2012;4:330-349.

2. Hinton DR, He S, Lopez PF. Apoptosis in surgically excised choroidal neovascular membranes in age-related macular degeneration. Arch Ophthalmol 1998;116:203-209.

3. Obulesu M, Lakshmi MJ. Apoptosis in Alzheimer's disease: an understanding of the physiology, pathology and therapeutic avenues. Neurochem Res 2014;39:23012312.

4. Samadi A, et al. Oxysterol species: reliable markers of oxidative stress in diabetes mellitus. J Endocrinol Invest 2019;42:7-17.

5. Thomas $\mathrm{CN}$, et al. Caspases in retinal ganglion cell death and axon regeneration. Cell Death Discov 2017;3:17032.

6. Xu GZ, Li WW, Tso MO. Apoptosis in human retinal degenerations. Trans Am Ophthalmol Soc 1996;94:411430; discussion 430-431.

7. Wei $Q$, et al. Combination of bevacizumab and photodynamic therapy vs. bevacizumab monotherapy for the treatment of wet age-related macular degeneration: A meta-analysis of randomized controlled trials. Exp Ther Med 2018;16:1187-1194. 
8. Pariente A, et al. Inflammatory and cell death mechanisms induced by 7-ketocholesterol in the retina. Implications for age-related macular degeneration. Exp Eye Res 2019;187:107746.

9. Rodriguez IR, Larrayoz IM. Cholesterol oxidation in the retina: implications of $7 \mathrm{KCh}$ formation in chronic inflammation and age-related macular degeneration. $J$ Lipid Res 2010;51:2847-2862.

10. Yang $\mathrm{C}$, et al. 7-Ketocholesterol disturbs RPE cells phagocytosis of the outer segment of photoreceptor and induces inflammation through ERK signaling pathway. Exp Eye Res 2019;189:107849.

11. Indaram $\mathrm{M}$, et al. 7-Ketocholesterol increases retinal microglial migration, activation, and angiogenicity: a potential pathogenic mechanism underlying age-related macular degeneration. Sci Rep 2015;5:9144.

12. Larrayoz IM, et al. 7-ketocholesterol-induced inflammation: involvement of multiple kinase signaling pathways via NFkappaB but independently of reactive oxygen species formation. Invest Ophthalmol Vis Sci 2010;51:4942-4955.

13. Wang $\mathrm{H}$, et al. Thy-1 Regulates VEGF-Mediated Choroidal Endothelial Cell Activation and Migration: Implications in Neovascular Age-Related Macular Degeneration. Invest Ophthalmol Vis Sci 2016;57:5525-5534.

14. Moreira EF, et al. 7-Ketocholesterol is present in lipid deposits in the primate retina: potential implication in the induction of VEGF and CNV formation. Invest Ophthalmol Vis Sci 2009;50:523-532.

15. Dulak J, et al. Vascular endothelial growth factor synthesis in vascular smooth muscle cells is enhanced by 7-ketocholesterol and lysophosphatidylcholine independently of their effect on nitric oxide generation. Atherosclerosis 2001;159:325-332.

16. Gramajo AL, et al. Mitochondrial DNA damage induced by 7-ketocholesterol in human retinal pigment epithelial cells in vitro. Invest Ophthalmol Vis Sci 2010;51:1164-1170.

17. Luthra $\mathrm{S}$, et al. 7-Ketocholesterol activates caspases-3/7, 8 , and -12 in human microvascular endothelial cells in vitro. Microvasc Res 2008;75:343-350.

18. Luthra $\mathrm{S}$, et al. Activation of caspase-8 and caspase-12 pathways by 7-ketocholesterol in human retinal pigment epithelial cells. Invest Ophthalmol Vis Sci 2006;47:5569_ 5575.

19. Neekhra A, et al. Caspase-8, -12, and -3 activation by 7-ketocholesterol in retinal neurosensory cells. Invest Ophthalmol Vis Sci 2007;48:1362-1367.

20. Javitt NB, Javitt JC. The retinal oxysterol pathway: a unifying hypothesis for the cause of age-related macular degeneration. Curr Opin Ophthalmol 2009;20:151-157.

21. Brahmi F, et al. Prevention of 7-ketocholesterol-induced side effects by natural compounds. Crit Rev Food Sci Nutr 2018:1-20.

22. Dugas B, et al. Effects of oxysterols on cell viability, inflammatory cytokines, VEGF, and reactive oxygen species production on human retinal cells: cytoprotective effects and prevention of VEGF secretion by resveratrol. Eur J Nutr 2010;49:435-446.

23. Sun W, Seigel GM, Salvi RJ. Retinal precursor cells express functional ionotropic glutamate and GABA receptors. Neuroreport 2002;13:2421-2424.

24. Seigel GM. Review: R28 retinal precursor cells: the first 20 years. Mol Vis 2014;20:301-306.
25. Dunn KC, et al. ARPE-19, a human retinal pigment epithelial cell line with differentiated properties. Exp Eye Res 1996;62:155-169.

26. Moustafa MT, et al. Protective Effects of memantine on hydroquinone-treated human retinal pigment epithelium cells and human retinal muller cells. $J$ Ocul Pharmacol Ther 2017;33:610-619.

27. Lee JW, Huang JD, Rodriguez IR. Extra-hepatic metabolism of 7-ketocholesterol occurs by esterification to fatty acids via CPLA2alpha and SOAT1 followed by selective efflux to HDL. Biochim Biophys Acta 2015;1851:605-619.

28. Rodriguez IR, et al. 7-ketocholesterol accumulates in ocular tissues as a consequence of aging and is present in high levels in drusen. Exp Eye Res 2014;128:151-155.

29. Jang ER, Lee CS. 7-ketocholesterol induces apoptosis in differentiated PC12 cells via reactive oxygen speciesdependent activation of NF-kappaB and Akt pathways. Neurochem Int 2011;58:52-59.

30. Pedruzzi $E$, et al. $\mathrm{NAD}(\mathrm{P}) \mathrm{H}$ oxidase Nox-4 mediates 7-ketocholesterol-induced endoplasmic reticulum stress and apoptosis in human aortic smooth muscle cells. Mol Cell Biol 2004;24:10703-10717.

31. Shimozawa $M$, et al. 7-Ketocholesterol enhances the expression of adhesion molecules on human aortic endothelial cells by increasing the production of reactive oxygen species. Redox Rep 2004;9:370-375.

32. Ong JM, et al. Oxysterol-induced toxicity in R28 and ARPE19 cells. Neurochem Res 2003;28:883-891.

33. Casson RJ. Possible role of excitotoxicity in the pathogenesis of glaucoma. Clin Exp Ophthalmol 2006;34:54-63.

34. Heinen-Kammerer $\mathrm{T}$, et al. Added therapeutic value of memantine in the treatment of moderate to severe Alzheimer's disease. Clin Drug Investig 2006;26:303-314.

35. Kim TW, et al. Neuroprotective effect of memantine in a rabbit model of optic nerve ischemia. Korean J Ophthalmol 2002;16:1-7.

36. Lipton SA, Rosenberg PA. Excitatory amino acids as a final common pathway for neurologic disorders. N Engl J Med 1994;330:613-622.

37. WoldeMussie E, et al. Neuroprotective effect of memantine in different retinal injury models in rats. J Glaucoma 2002;11:474-480.

38. Chen B, et al. Memantine attenuates cell apoptosis by suppressing the calpain-caspase-3 pathway in an experimental model of ischemic stroke. Exp Cell Res 2017;351:163-172.

39. Ota $\mathrm{H}$, et al. Protective effects of NMDA receptor antagonist, memantine, against senescence of $\mathrm{PC} 12$ cells: a possible role of nNOS and combined effects with donepezil. Exp Gerontol 2015;72:109-116.

40. Jantas-Skotniczna D, Kajta M, Lason W. Memantine attenuates staurosporine-induced activation of caspase3 and LDH release in mouse primary neuronal cultures. Brain Res 2006;1069:145-153.

41. Seigel GM, et al. Neuronal gene expression and function in the growth-stimulated R28 retinal precursor cell line. Curr Eye Res 2004;28:257-269. 
42. Jantas D, et al. An involvement of BDNF and PI3-K/Akt in the anti-apoptotic effect of memantine on staurosporineevoked cell death in primary cortical neurons. Apoptosis 2009;14:900-912.

43. Dias IHK, et al. Simvastatin reduces circulating oxysterol levels in men with hypercholesterolaemia. Redox Biol 2018;16:139-145.

44. Franke $\mathrm{C}$, et al. $\mathrm{Bcl}-2$ upregulation and neuroprotection in guinea pig brain following chronic simvastatin treatment. Neurobiol Dis 2007;25:438-445.

45. Johnson-Anuna $L N$, et al. Simvastatin protects neurons from cytotoxicity by up-regulating Bcl-2 mRNA and protein. J Neurochem 2007;101:77-86.

46. Kretz A, et al. Simvastatin promotes heat shock protein 27 expression and Akt activation in the rat retina and protects axotomized retinal ganglion cells in vivo. Neurobiol Dis 2006;21:421-430.

47. Miyahara S, et al. Simvastatin inhibits leukocyte accumulation and vascular permeability in the retinas of rats with streptozotocin-induced diabetes. Am J Pathol 2004;164:1697-1706.

48. Muck AO, Seeger H, Wallwiener D. Class-specific proapoptotic effect of statins on human vascular endothelial cells. Z Kardiol 2004;93:398-402.

49. Urbich $C$, et al. Double-edged role of statins in angiogenesis signaling. Circ Res 2002;90:737-744.

50. Weis $M$, et al. Statins have biphasic effects on angiogenesis. Circulation 2002;105:739-745.

51. Boucher $\mathrm{K}$, et al. HMG-CoA reductase inhibitors induce apoptosis in pericytes. Microvasc Res 2006;71:91-102.

52. Fujino $\mathrm{M}$, et al. Counteracting effects of high density lipoprotein-cholesterol subfractions on statin-induced growth arrest. Cardiovasc Drugs Ther 2005;19:113-118.
53. Krikorian R, et al. Concord grape juice supplementation improves memory function in older adults with mild cognitive impairment. Br J Nutr 2010;103:730-74.

54. Steffen $\mathrm{Y}$, et al. Protein modification elicited by oxidized low-density lipoprotein (LDL) in endothelial cells: protection by (-)-epicatechin. Free Radic Biol Med 2007;42:955-970.

55. Steffen $\mathrm{Y}$, Schewe T, Sies H. Epicatechin protects endothelial cells against oxidized LDL and maintains NO synthase. Biochem Biophys Res Commun 2005;331:12771283.

56. Wang $\mathrm{MH}$, et al. (-)-Epigallocatechin-3-gallate decreases the impairment in learning and memory in spontaneous hypertension rats. Behav Pharmacol 2012;23:771-780.

57. Zhang B, Osborne NN. Oxidative-induced retinal degeneration is attenuated by epigallocatechin gallate. Brain Res 2006;1124:176-187.

58. $\mathrm{Li} \mathrm{S}$, et al. Characterization of the responses of the caspase 2, 3, 6 and 8 genes to immune challenges and extracellular ATP stimulation in the Japanese flounder (Paralichthys olivaceus). BMC Vet Res 2019;15:20.

59. Li GY, Fan B, Su GF. Acute energy reduction induces caspase-dependent apoptosis and activates p53 in retinal ganglion cells (RGC-5). Exp Eye Res 2009;89:581-589.

60. Mansoor S, et al. Inhibition of apoptosis in human retinal pigment epithelial cells treated with benzo(e)pyrene, a toxic component of cigarette smoke. Invest Ophthalmol Vis Sci 2010;51:2601-2607.

61. Kozlowski MR. The ARPE-19 cell line: mortality status and utility in macular degeneration research. Curr Eye Res 2015;40:501-509. 